\title{
Changes in Mean and Genetic Variance During Two Cycles of Within-family Selection in Switchgrass
}

\author{
Michael D. Casler
}

Published online: 28 January 2010

(C) US Government 2010

\begin{abstract}
Switchgrass (Panicum virgatum L.) is a candidate for cellulosic bioenergy feedstock development. Because biomass yield is the most important biological factor limiting the commercial development and deployment of switchgrass as a cellulosic bioenergy feedstock efforts must be undertaken to develop improved cultivars. The objectives of this study were (1) to conduct two cycles of within-family selection for increased biomass yield in WS4U switchgrass and (2) to simultaneously evaluate progress from selection relative to the mean of the original WS4U population. Each of the $150 \mathrm{WS} 4 \mathrm{U}$ families was subjected to phenotypic selection for vigor, seed production, and disease resistance. The mean of all families increased relative to the original $\mathrm{WS} 4 \mathrm{U}$ population by $0.36 \mathrm{Mg} \mathrm{ha}^{-1}$ cycle $^{-1}$ for biomass yield and $3.0 \%$ cycle $^{-1}$ for ground cover. Gains were uniform across two diverse evaluation locations, indicating that selection gains were robust relative to some variation in Hardiness Zone and soil type. Two cycles of within-family selection led to a homogenization of the diverse families, creating novel recombinations and reducing the family genetic variance to near zero. It is hypothesized that selection and recombination has led to replication of favorable alleles across pedigrees with differing genetic backgrounds, increasing the likelihood of including these favorable alleles in the progeny of future selections. The rate of genetic progress is expected to increase in future cycles of selection with a combination of within-family phenotypic selection and half-sib progeny testing of selected families.
\end{abstract}

M. D. Casler $(\triangle)$

USDA-ARS, U.S. Dairy Forage Research Center,

1925 Linden Dr,

Madison, WI 53706-1108, USA

e-mail: michael.casler@ars.usda.gov
Keywords Panicum virgatum L · Biomass yield . Breeding $\cdot$ Biofuel crops

\section{Introduction}

Switchgrass (Panicum virgatum L.) is a candidate for cellulosic bioenergy feedstock development in some parts of the USA and Canada. Switchgrass is widely adapted to many habitats east of the North American Rocky Mountains. Feedstock development of switchgrass was initiated by the U.S. Department of Energy in 1992, with expansion to USDA-ARS in 2002, and later addition of significant Department of Energy competitive grant programs [16]. With the increase in research on this native species, and subsequent improvements in management efficiency, public and commercial interest in switchgrass production has increased accordingly [16].

Early adoption and deployment of switchgrass for bioenergy production has been based on existing cultivars, developed as seed increases of prairie remnant populations or from a limited number of selection cycles in forage breeding programs [19]. Switchgrass cultivars are highly photoperiodic and vary considerably in adaptation to local climatic conditions, resulting in regional deployment patterns that reflect the geographic origins of most cultivars. Most improved cultivars originate from accessions and breeding programs within the Great Plains region of North America. East of the Great Plains, the vast majority of commercial switchgrass seed deployment originates from unimproved seed increases of prairie remnant populations. These cultivars have been modestly successful because they originate from a wide array of geographic regions and many of them have modestly broad adaptation ranges, despite their "unimproved" status. 
Regional deployment of switchgrass cultivars is essential, because of these differential adaptations. Most cultivars can be deployed effectively within bands that include one hardiness zone north and south of their origin [6]. Differences in humidity, precipitation, and soil types between the Great Plains and eastern North America suggest that different cultivars be deployed in these regions. Differences in biomass yield and disease resistance between easternand western-derived cultivars support this assessment $[2,9$, $10,24]$. Overall, a combination of hardiness zones and ecoregions provides a useful template for choosing switchgrass cultivars with the highest likelihood of adaptation to individual field sites [23].

Biomass yield is the most important biological factor limiting the commercial development and deployment of switchgrass as a cellulosic bioenergy feedstock. Profitability of biomass production from switchgrass is directly linked to biomass yield. Production costs may decrease as switchgrass growers gain experience, but increasing biomass yield is the most effective mechanism of decreasing cost per unit of biomass produced [14]. Biomass yield is a heritable trait in switchgrass and improvements can be made by phenotypic selection of individual plants with high yield potential $[7,12,15]$.

The WS4U population of switchgrass is a broad-based germplasm pool made up of 152 tetraploid upland-cytotype parents of diverse origins [5]. Individual plants are obligate outcrossing and genetic improvements are made by identification of a small frequency of superior individuals, followed by intercrossing and germination of progeny seed to begin a new generation (cycle) of selection. Based upon the origin of the parental plants, selections derived from WS4U are expected to be adapted to Hardiness Zones 3-5 east of the Great Plains region of North America. The WS4U population was created as a germplasm base to select and breed for increased biomass yield of switchgrass in this region. The objectives of this study were (1) to conduct two cycles of within-family selection for increased biomass yield in WS4U switchgrass and (2) to simultaneously evaluate progress from selection relative to the mean of the original WS4U population.

\section{Methods}

Seed of each original WS4U polycross (half-sib) family was produced at Arlington, WI in September 2000. Each of the 152 parents was present in two vegetative propagules and seed was bulked between the two replicates. The crossing block was isolated by at least $5 \mathrm{~km}$ from all other flowering switchgrass, eliminating the possibility of contamination. Seed samples were tested for germination using standard protocols [1].

\section{Biomass Yield Trials}

Plots of each family were established at two locations in May 2001 using a seeding rate of 400 pure live seeds $\mathrm{m}^{-2}$. Seeds were planted in $0.9-\times 1.4-\mathrm{m}$ plots that consisted of five drilled rows, spaced $15 \mathrm{~cm}$ apart with seed placed at a depth of 5 to $10 \mathrm{~mm}$. The experimental design was a randomized complete block with two replicates at each location. Locations were Arlington, WI [Plano silt loam (fine-silty, mixed, mesic Typic Argiudoll); $43.302^{\circ} \mathrm{N}$, $89.353^{\circ} \mathrm{W}$; USDA Hardiness Zone 4] and Marshfield, WI [Withee silt loam (fine-loamy, mixed, superactive, frigid Aquic Glossudalf); $44.643^{\circ} \mathrm{N}, 90.138^{\circ} \mathrm{W}$; USDA Hardiness Zone 3]. In addition to each family, each block contained one plot each of the cultivars Blackwell, Carthage, Cave-inRock, Forestburg, Pathfinder, Sunburst, and Trailblazer, and four plots each of the base population WS4U-C0.

Plots were fertilized with $112 \mathrm{~kg} \mathrm{~N} \mathrm{ha}^{-1}$ prior to the initiation of growth in spring 2002 and 2003. Plots were harvested with a flail-type harvester in late August 2002 and 2003, approximately 2 weeks post-anthesis, at a cutting height of approximately $8 \mathrm{~cm}$. A biomass sample of 400 to $500 \mathrm{~g}$ was taken from each plot for dry matter determination after drying at $60^{\circ} \mathrm{C}$ in a forced-air dryer. Prior to harvesting, each plot was rated for stage of reproductive maturity, using a numerical scale that ranged from 3.0 for the boot stage to 4.3 for the soft dough stage [13]. Ground cover was determined immediately after each harvest using two placements of a 25-cell grid [22].

\section{Spaced-plant Selection Nurseries}

Seeds of each family were germinated in a glasshouse in January 2001 and transplanted to the field in May 2001. The experimental design of the spaced-plant nursery was a randomized complete block with four replicates. Each plot consisted of ten plants from one family, transplanted on a $0.3-\mathrm{m}$ spacing within plots and $0.9-\mathrm{m}$ spacing between plots. Weeds were controlled by application of $1.12 \mathrm{~kg} \mathrm{ha}^{-1}$ alachlor [2-chloro-N-2,6-diethylphenyl)- $N$-(methoxymethyl)acetamide] with $0.07 \mathrm{~kg} \mathrm{ha}^{-1}$ imazethapyr $\{( \pm)-2-[4$, 5-dihydro-4-methyl-4-(1-methylethyl)-5-oxo-1H-imidazol2-yl]-5-ethyl-3-pyridinecarboxylic acid\}. All biomass was removed in September 2001 prior to the onset of winter.

Each plant was fertilized with $112 \mathrm{~kg} \mathrm{~N} \mathrm{ha}^{-1}$ prior to the initiation of growth in spring 2002. Preemergence herbicides were also applied prior to initiation of growth, exactly as described for the 2001 application. Prior to anthesis eight plants were culled from the ten present in each plot using a sickle-bar mower. Selection was based almost exclusively on visual estimation of biomass yield. The remaining $20 \%$ of the nursery was allowed to pollinate in isolation from other sources of switchgrass. Seed was harvested in late 
September on one plant of each row-selection based on visual biomass, seed production, and disease reaction - and bulked across the four replicates within a family, creating 150 new seed bulks (families). Two families were permanently lost due to a combination of poor germination in the glasshouse and in the five-row drill plots.

\section{Second Selection Cycle}

Seed of the 150 families that completed Cycle 1 in 2002, harvested from the spaced-plant selection nursery, were used to initiate a second cycle of selection in 2003, exactly as described for Cycle 1, except that the five-row drill plots were planted in three replicates per location instead of two. Drill-plots were established in 2003 and harvested in 20045. The spaced-plant nursery was established in 2003, selection was practiced in 2004, and 150 new families were created to complete Cycle 2 in 2004. The 150 Cycle-2 families were used to establish drill plots at Arlington and Marshfield in 2005, as described for Cycle 2. These plots were harvested for biomass yield in 2006-7.

\section{Statistical Analysis}

Biomass yield, ground cover, dry matter concentration, and maturity stage were analyzed by nearest neighbor analysis for each cycle-location-year combination using the preadjustment of total forage yield [17]. Previous research at these two locations has demonstrated that there is a high level of seemingly random spatial variation for biomass yields, which is largely unpredictable for blocking designs that require some knowledge of field gradients [17]. Nearest-neighbor methods have been shown to be fairly efficient at controlling a large portion of this variability and providing effective adjustments to family means. The first adjustment consisted of a covariance adjustment for spatial variation within each cycle-location-year combination. The second adjustment was to subtract the mean of the original WS4U population from each plot value within each cyclelocation-year combination, providing a deviation of each family value from the mean of the original population. Adjusted values of biomass yield were analyzed by analysis of variance using the split-plot-in-time model [18]. Degrees of freedom in these models were subtracted from pooled experimental errors, according to the number of parameters fit in the spatial models for each cycle-location-year combination [3]. Experimental error mean squares and all $F$-tests were recomputed in a spreadsheet after adjustment of error degrees of freedom. Blocks were assumed to have a random effect and all other effects were fixed (Table 1). Family variance components and confidence intervals were estimated from combined analyses of variance within each cycle using mixed models analysis [8]. Nine families were excluded from these statistical analyses due to inconsistent germination and establishment in one or more cycles of selection, resulting in a balanced structure with 141 families across selection cycles and evaluation locations.

\section{Results and Discussion}

Separate analyses of variance computed on biomass yield of 1-year-old vs. 2-year-old plots resulted in a general lack of significance for cycles and families. Recomputation of the analysis of variance based on 2-year means resulted in significant differences among cycles and families (Table 1), indicating significantly improved precision associated with 2-year mean biomass yield of switchgrass. Routine field
Table 1 Analysis of variance for 2-year mean biomass yield and 2 nd-year ground cover of 141 switchgrass families evaluated across two cycles of selection at Arlington and Marshfield, WI

\begin{tabular}{|c|c|c|c|c|c|c|c|}
\hline \multirow[t]{2}{*}{ Source of variation } & \multirow[t]{2}{*}{$\mathrm{df}$} & \multicolumn{3}{|c|}{ Biomass yield } & \multicolumn{3}{|c|}{ Ground cover } \\
\hline & & MS & $F$-ratio & $P$-value & MS & $F$-ratio & $P$-value \\
\hline Cycle-linear (CL) & 1 & 191.67 & 9.61 & 0.0147 & 4269.5 & 12.50 & 0.0077 \\
\hline Cycle-residual (CR) & 1 & 16.34 & 0.82 & 0.3919 & 67.6 & 0.20 & 0.6682 \\
\hline Location (L) & 1 & 247.86 & 12.42 & 0.0078 & 2424.2 & 7.10 & 0.0286 \\
\hline $\mathrm{L} \times \mathrm{CL}$ & 1 & 40.54 & 2.03 & 0.1919 & 910.6 & 2.67 & 0.1412 \\
\hline $\mathrm{L} \times \mathrm{CR}$ & 1 & 39.38 & 1.97 & 0.1977 & 335.8 & 0.98 & 0.3505 \\
\hline $\mathrm{C} \times$ Block $/ \mathrm{L}$ & 8 & 19.95 & 6.08 & $<0.0001$ & 341.6 & 1.87 & 0.0617 \\
\hline Family (F) & 140 & 4.66 & 1.42 & 0.0017 & 357.2 & 1.95 & $<0.0001$ \\
\hline $\mathrm{F} \times \mathrm{CL}$ & 140 & 4.58 & 1.40 & 0.0028 & 366.5 & 2.00 & $<0.0001$ \\
\hline $\mathrm{F} \times \mathrm{CR}$ & 140 & 5.08 & 1.55 & $<0.0001$ & 273.4 & 1.49 & 0.0004 \\
\hline $\mathrm{F} \times \mathrm{L}$ & 140 & 3.95 & 1.20 & 0.0638 & 268.6 & 1.47 & 0.0007 \\
\hline $\mathrm{F} \times \mathrm{L} \times \mathrm{CL}$ & 140 & 3.14 & 0.96 & 0.6228 & 249.2 & 1.36 & 0.0052 \\
\hline $\mathrm{F} \times \mathrm{L} \times \mathrm{CL}$ & 140 & 2.99 & 0.91 & 0.7556 & 169.6 & 0.93 & 0.7125 \\
\hline Pooled error & 1,108 & 3.28 & & & 183.0 & & \\
\hline
\end{tabular}


evaluations of switchgrass biomass yield should be conducted for a minimum of 2 years because up to 2 years are required for switchgrass to reach its biomass yield potential [19], not all switchgrass genotypes possess the levels of stress tolerances required for long-term survival [21], and 2 years may be necessary to provide adequate precision for detecting differences among genotypes or families (Table 1).

Genetic variation among families was significant for ground cover measured in the second harvest year. Family differences were not significant for dry matter concentration or stage of reproductive maturity within the original population or within any subsequent cycles of selection. This was due not to a lack of precision or repeatability of these measurements, but to a lack of true differences, owing to the fact that error mean squares were similar for this experiment and other comparable switchgrass field studies at these locations $[3,6]$.

Subtracting the mean of WS4U from each family within each cycle allowed estimation of changes in biomass yield during two cycles of selection, based on averages across all 141 families. The linear effect of cycles was significant,
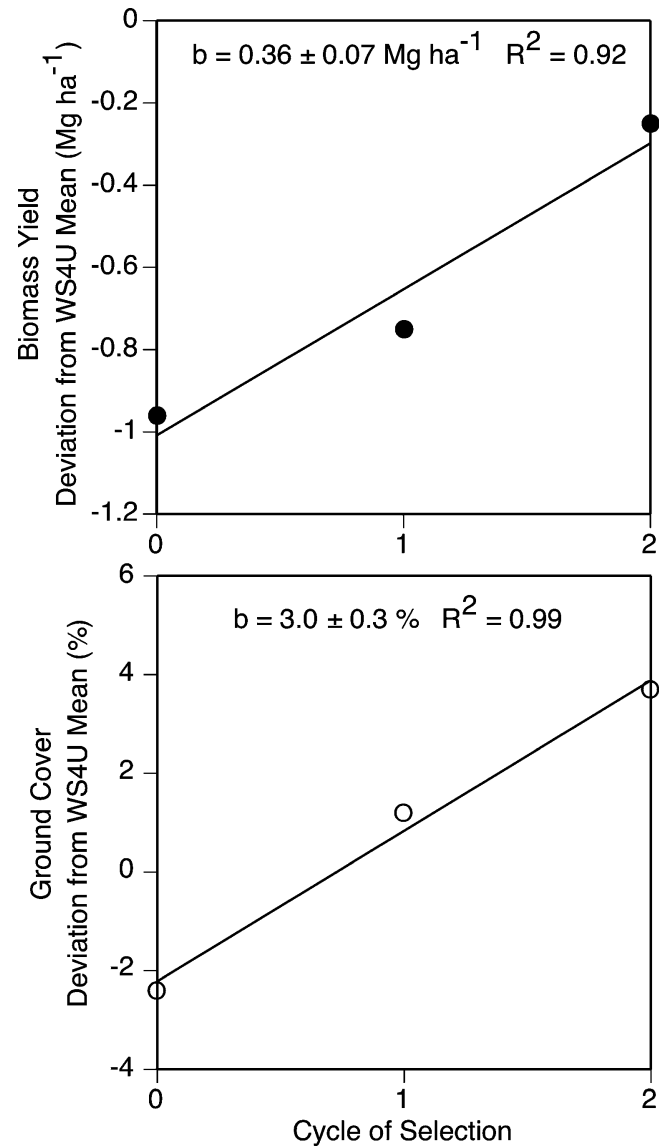

Fig. 1 Linear regression of mean biomass yield for 141 families of WS4U, expressed as a deviation from the WS4U base population mean, across two cycles of within-family phenotypic selection for plant vigor

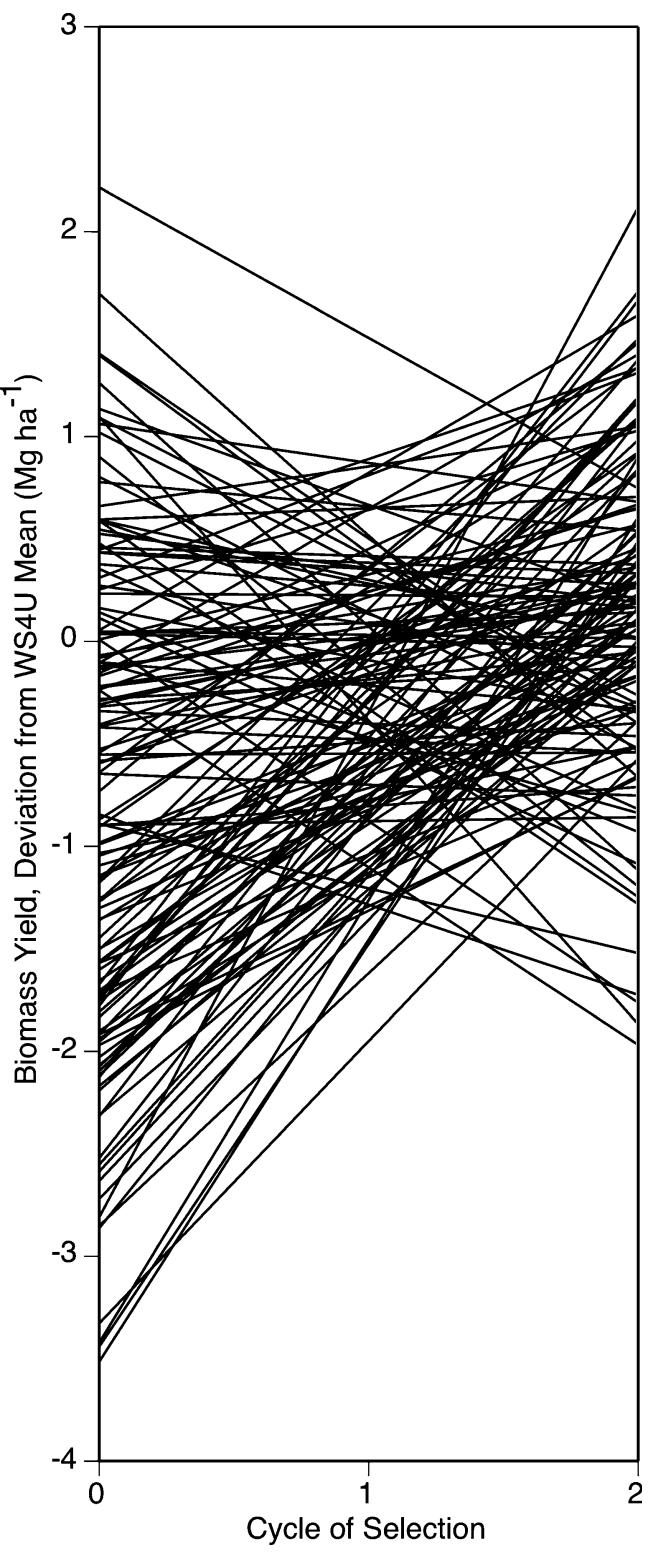

Fig. 2 Regressions of mean biomass yield, expressed as a deviation from the WS4U base population mean, across two cycles of withinfamily phenotypic selection for plant vigor. Each regression line corresponds to one of the 141 families, measured in Cycles 0, 1, and 2

accounting for $92 \%$ of the sum of squares for cycles (Table 1 ). The nonlinear or residual component was not significant. Relative to the mean of the WS4U population, mean biomass yield of the families increased by an average of $0.36 \pm 0.07 \mathrm{Mg} \mathrm{ha}^{-1}$ cycle $^{-1}$ (Fig. 1). Similarly, mean ground cover of the families increased by an average of $3.0 \pm 0.3$ percentage units cycle ${ }^{-1}$ (Fig. 1). Ground cover and biomass yield were positively correlated with each other, with phenotypic correlation coefficients ranging from $r=0.22$ to $0.77(P<0.01)$.

These effects were consistent between the two locations, despite the fact that all selection occurred at Arlington and 


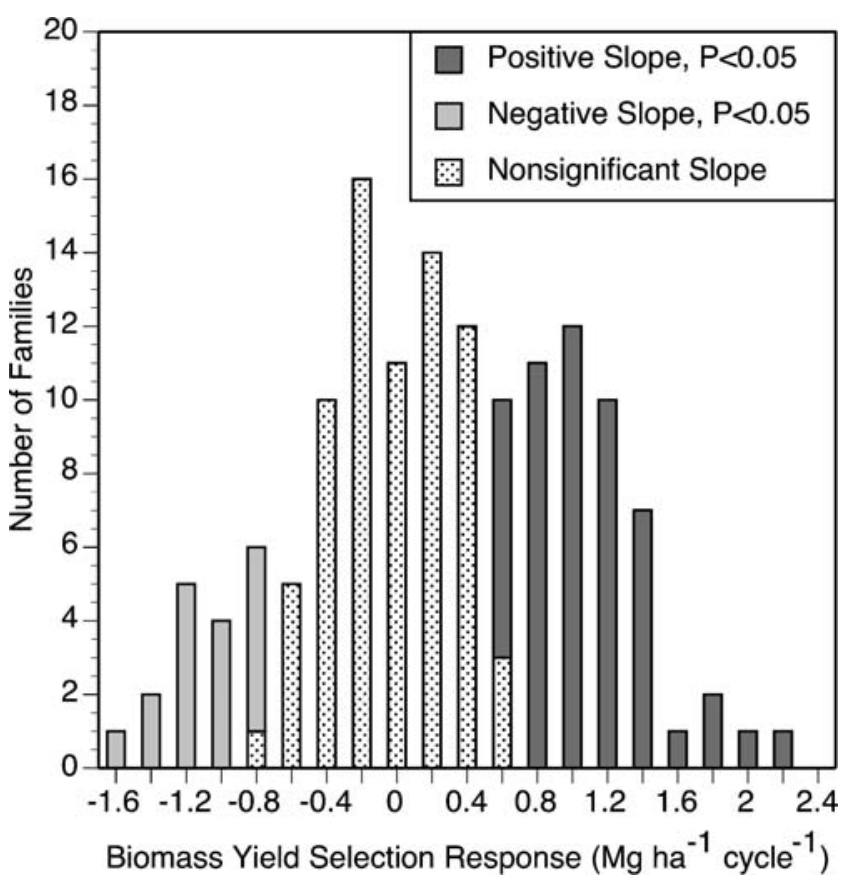

Fig. 3 Distribution of linear regression slopes for mean biomass yield of 141 switchgrass families, expressed as a deviation from the WS4U base population mean, across two cycles of within-family phenotypic selection for plant vigor the two locations differed in soil type and hardiness zone. Consistent selection responses across locations indicated that gains in switchgrass biomass yield may be relatively robust with respect to some environmental factors. This was also observed for switchgrass selections created in Nebraska and evaluated in Iowa and Indiana, with positive selection responses observed at locations with different environmental conditions compared to the selection location [7]. Similarly, selections for high biomass yield in a low-productivity environment were consistently higher in biomass yield to selections made in a high-productivity environment regardless of where they were grown [15].

Gains in 2-year mean biomass yield associated with withinfamily selection were partly due to increases in 2-year survival rates. Previous research has indicated that most switchgrass mortality in the north-central USA occurs as a result of winter injury and lack of sufficient cold tolerance $[4,21]$. Although Arlington and Marshfield belong to two different hardiness zones (HZ four and three, respectively), the Arlington location was sufficiently severe to provide selection pressure for survival within both hardiness zones. This is a very significant finding, because it verifies that genetic gains for switchgrass survival and biomass yield can be made across adjacent hardiness zones, based on selection at a single location. This finding provides additional
Fig. 4 Estimated variance components and $95 \%$ confidence limits (UL $=$ upper limit, $\mathrm{LL}=$ lower limit) for residual and family variances of 2-year mean biomass yield and 2ndyear ground cover measured on 141 switchgrass families subjected to two cycles of withinfamily phenotypic selection for plant vigor
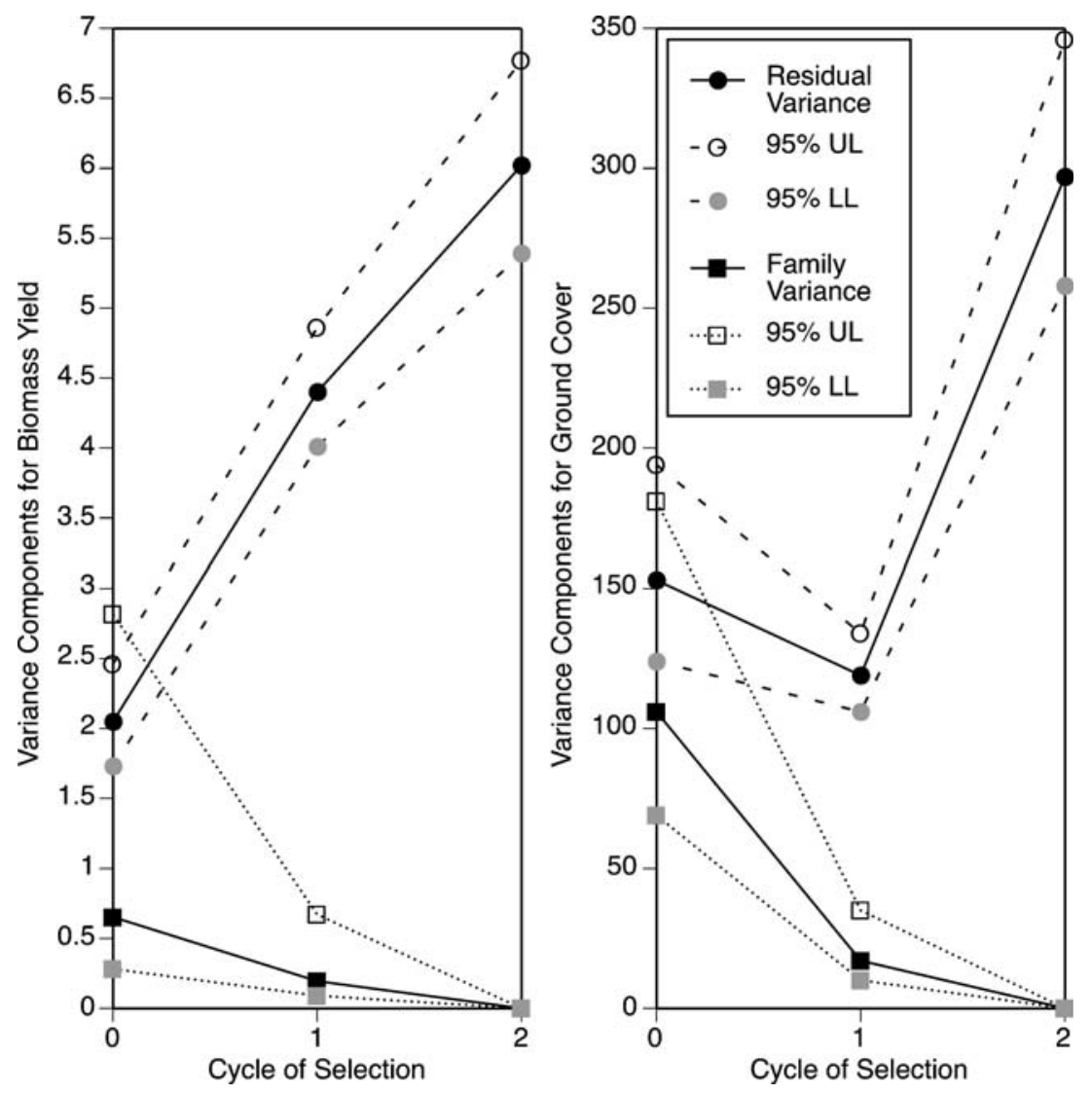
verification that switchgrass cultivars can generally be used one hardiness zone north or south or their origin without expectation of severe losses in fitness [6].

Although families differed in mean biomass yield, the dominant source of variation for families was the family $x$ cycle interaction, particularly for biomass yield (Table 1). Approximately half of this interaction could be explained by differences in linear response to selection within the 141 families. Families expressed dramatic differences in response to selection (Fig. 2), ranging in biomass yield response from -1.53 to $+2.36 \mathrm{Mg} \mathrm{ha}^{-1}$ cycle $^{-1}$ relative to the WS4U base population. There was a strong negative phenotypic correlation, $r=-0.84 \quad(P<0.0001)$, between mean biomass yield in Cycle 0 and the linear response of biomass yield to selection. Responses were very similar for ground cover ( $r=0.42, P<0.0001$, between biomass yield and ground cover selection responses), but were not shown due to redundancy.

The within-family selection protocol acted to homogenize the entire population of families across two cycles of selection. Families that expressed relatively low initial biomass yield potential showed the greatest improvement in biomass yield across the two cycles of selection. Selection was most effective in these families for two reasons: (1) pollination from superior families resulted in rapid increases in frequency of favorable alleles for biomass yield and (2) visual selection for high biomass yield (plant vigor) within these families was favored by the relatively high frequency of plants with obviously low vigor. Conversely, families with the highest biomass yield presented the greatest difficulty for within-family selection for the two opposite reasons: (1) pollen from the general population rapidly diluted the favorable allelic structure of these families and (2) visually choosing the best plants within these families was often extremely difficult due to their uniformly high vigor and stature.

A small number of families appeared to be very resilient with respect to mean biomass yield across selection cycles, retaining a high ranking of biomass yield in all three cycles (Fig. 2). For example, six families ranked within the upper quartile within the original population and after both cycles of selection. These families most likely maintained a high rank across selection cycles due to the balancing effect of positive selection pressure for high plant biomass offsetting the diluting effect of unfavorable alleles from pollen shed by families with relatively low biomass yield potential.

In this within-family selection scheme, selection was practiced independently on maternal plants within each family line. Essentially, each family became a subpopulation maintained within the megapopulation, connected by a common selection criterion and by a common source of pollen. Of the 141 families, 72 showed no evidence of a change in mean biomass yield relative to the WS4U base population (Fig. 3). Seventeen families had a significant decrease in mean biomass yield, averaging $-0.99 \pm$ $0.06 \mathrm{Mg} \mathrm{ha}^{-1}$ cycle $^{-1}$. These families had a mean biomass yield, relative to WS4U, of $0.81 \pm 0.17 \mathrm{Mg} \mathrm{ha}^{-1}$ in Cycle 0, decreasing to $-1.17 \pm 0.20 \mathrm{Mg} \mathrm{ha}^{-1}$ in Cycle 2. Fifty-two families had a significant increase in mean biomass yield, averaging $+1.18 \pm 0.05 \mathrm{Mg} \mathrm{ha}^{-1}$ cycle $^{-1}$. These families had a mean biomass yield, relative to $\mathrm{WS} 4 \mathrm{U}$, of $-2.27 \pm$ $0.14 \mathrm{Mg} \mathrm{ha}^{-1}$ in Cycle 0, increasing to $+0.09 \pm$ $0.11 \mathrm{Mg} \mathrm{ha}{ }^{-1}$ in Cycle 2. For ground cover (data not shown), 83 families showed no evidence of a change in mean relative to the WS4U base population (Fig. 3). Thirteen families had a significant decrease in mean ground cover, averaging $-7.4 \pm 04 \%$ cycle $^{-1}$. These families had a mean ground cover, relative to WS4U, of $6.9 \pm 1.2 \%$ in
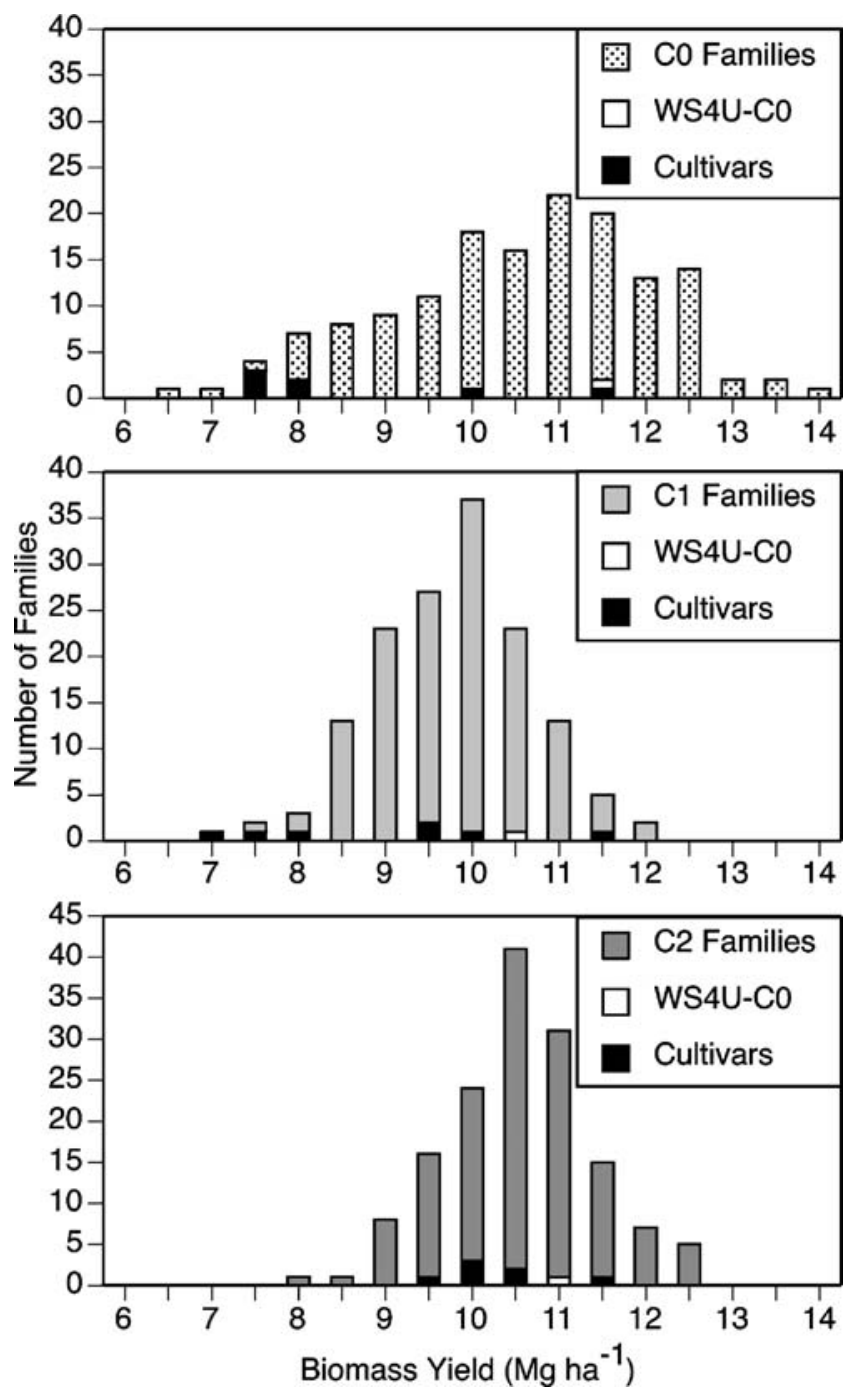

Fig. 5 Histograms of mean biomass yield for 141 WS4U switchgrass families in the original base population (Cycle 0) and following two cycles of within-family phenotypic selection for plant vigor 
Cycle 0, decreasing to $-7.9 \pm 1.5 \%$ in Cycle 2 . Forty-five families had a significant increase in mean ground cover, averaging $+11.7 \pm 1.1 \%$ cycle $^{-1}$. These families had a mean ground cover, relative to WS4U, of $-13.2 \pm 2.3 \%$ in Cycle 0 , increasing to $+10.2 \pm 1.0 \%$ in Cycle 2 .

In the short term, maintenance of all families within the WS4U population attenuated genetic gains in biomass yield of the entire population by allowing plants from lowyielding families to contribute to the pollen load. Had lowyielding families been eliminated during each cycle of selection, genetic gains would likely have been higher than those observed in this experiment. However, in the long term, this strategy has stored a considerable amount of genetic variability within families, each composed of a mixture of four half-sib families.

The net result of these two cycles of selection has been to nearly exhaust the genetic variation among families (Fig. 4). The reduction in genetic variance among families has resulted from two phenomena. First, a reduction in phenotypic variation among family means has occurred for both biomass yield and ground cover (Fig. 5). Most of this reduction occurred in the first cycle of selection with the bulking of four half-sib families across the four replicates to create families for the next cycle of selection. Second, as phenotypic variability among families decreased, the increased uniformity among families resulted in increasing errors associated with measurement of family mean yield (Fig. 4). Together, the decreased phenotypic variance and increased error variances combined to create a uniform set of families that differ principally in their origin. Indirectly, these observations indicate the lack of importance of maternal effects in regulating biomass yield and ground cover within this switchgrass population, supporting results from hybrid evaluation experiments $[11,20]$.

In the long-term, maintenance of all family pedigrees within the WS4U population has resulted in genetic recombinations that did not previously exist within the original source materials for this population. This selection and mating system has likely retained a high frequency of alleles that would have been rapidly lost with a traditional among-family selection system that eliminated a large proportion of each family pedigree in each cycle of selection. Bulking of half-sib families within the original 150 maternal pedigrees and forcing all selection to occur within these pedigrees has homogenized the pedigrees to a point where each pedigree has a very high likelihood of possessing superior plants and contributing superior alleles to the next generation. The initial population, following only a single cycle of random mating, may have expressed some heterosis for biomass yield and other traits, but the frequent recombinations among all maternal lines has ensured that this phenomenon is not a factor contributing to the genetic gains observed in this population.
To best utilize the existing genetic structure of this population, future selection efforts in the WS4U population must focus on extraction of superior phenotypes, genotypes, and alleles from within families. The classic genetic structure of a population of half-sib families (3:1 ratio of additive genetic variance within versus among families) can be restored within a single generation simply by advancing one half-sib family per pedigree to the next generation, preferably by within-family selection. The existing structure of WS4U-C2 increases the likelihood that each of those half-sib families will carry favorable alleles from their maternal parent. Maintenance of all pedigrees and withinfamily selection has likely led to introgression of some favorable alleles into multiple pedigrees, increasing the number of genetic backgrounds in which some favorable alleles will be evaluated. Beginning in the next generation, selection among families or pedigrees should be an effective mechanism to concentrate these favorable alleles in a smaller number of pedigrees. Furthermore, the presence of some favorable alleles repeated across different pedigrees enhances the probably that they will be included in the next generation rather than lost due to phenotyping errors. Proper replication of half-sib family evaluations, including multiple locations, a minimum of two harvest years, multiple replicates, and proper experimental design with spatial analyses will be essential for discriminating among families for biomass yield and survival.

Acknowledgments I thank Andy Beal, Doug Foy, and Nick Baker for assistance with various aspects of this experiment and Mike Bertram of the Marshfield Agricultural Research Station for providing land and field-management support. This research was funded in part by USDA-ARS CRIS Project Nos. 3655-41000-003-00D and 365541000-004-00D, the University of Wisconsin Agricultural Research Stations, and the U.S. Department of Energy Great Lakes Bioenergy Research Center Grant DE-FC02-07ER64494.

\section{References}

1. Association of Official Seed Analysts (1998) Rules for seed testing. AOSA, Beltsville

2. Berdahl JD, Frank AB, Krupinsky JM, Carr PM, Hanson JD, Johnson HA (2005) Biomass yield, phenology, and survival of diverse switchgrass cultivars and experimental strains in western North Dakota. Agron J 97:549-555

3. Casler MD (1999) Spatial variation affects precision of perennial cool-season forage grass trials. Agron J 91:75-81

4. Casler MD, Buxton DR, Vogel KP (2002) Genetic modification of lignin concentration affects fitness of perennial herbaceous plants. Theor Appl Genet 104:127-131

5. Casler MD, Vogel KP, Beal AC (2006) Registration of WS4U and WS8U switchgrass germplasms. Crop Sci 46:998-999

6. Casler MD, Vogel KP, Taliaferro CM, Ehlke NJ, Berdahl JD, Brummer EC et al (2007) Latitudinal and longitudinal adaptation of switchgrass populations. Crop Sci 47:2249-2260

7. Hopkins AA, Vogel KP, Moore KJ, Johnson KD, Carlson IT (1995) Genotype effects and genotype by environment interac- 
tions for traits of elite switchgrass populations. Crop Sci 35:125132

8. Littel RC, Milliken GA, Stroup WW, Wolfinger RD (1996) SAS system for mixed models. SAS Institute, Inc, Cary

9. Madakadze IC, Coulman BE, McElroy AR, Stewart KA, Smith DL (1998) Evaluation of selected warm-season grasses for biomass production in areas with a short growing season. Bioresour Technol 65:1-12

10. Madakadze IC, Stewart KA, Peterson PR, Coulman BE, Smith DL (1999) Cutting frequency and nitrogen fertilization effects on yield and nitrogen concentration of switchgrass in a short season. Crop Sci 39:552-557

11. Martinez-Reyna JM, Vogel KP (2008) Heterosis in switchgrass: spaced plants. Crop Sci 48:1312-1320

12. Missaoui AM, Fasoula VA, Bouton JH (2005) The effect of low plant density on response to selection for biomass production in switchgrass. Euphytica 142:1-12

13. Moore KJ, Moser LE, Vogel KP, Waller SS, Johnson BE, Pedersen JF (1991) Describing and quantifying growth stages of perennial forage grasses. Agron J 83:1073-1077

14. Perrin R, Vogel K, Schmer M, Mitchell R (2008) Farm-scale production cost of switchgrass for biomass. BioEnergy Res 1:91-97

15. Rose LWIV, Das MK, Fuentes RG, Taliaferro CM (2007) Effects of high- vs. low-yield environments on selection for increased biomass yield of switchgrass. Euphytica 156:407-415
16. Sanderson MA, Adler PR, Boateng AA, Casler MD, Sarath G (2007) Switchgrass as a biofuels feedstock in the USA. Can J Plant Sci 86:1315-1325

17. Smith KF, Casler MD (2004) The use of spatially adjusted herbage yields during the analysis of perennial forage grass trials across locations. Crop Sci 44:56-62

18. Steel RGC, Torrie JH, Dickey DA (1997) Principles and procedures of statistics. A biometrical approach, 3rd edn. McGraw-Hill, New York, p 666

19. Vogel KP (2004) Switchgrass. In: Moser LE et al (eds) Warmseason (C4) grasses. ASA-CSSA-SSSA, Madison, pp 561588

20. Vogel KP, Mitchell RB (2008) Heterosis in switchgrass: biomass yield in swards. Crop Sci 48:2159-2164

21. Vogel KP, Hopkins AA, Moore KJ, Johnson KD, Carlson IT (2002) Winter survival in switchgrass populations bred for high IVDMD. Crop Sci 42:1857-1862

22. Vogel KP, Masters RA (2001) Frequency grid - a simple tool for measuring grassland establishment. J Range Manag 54:653655

23. Vogel KP, Schmer MR, Mitchell RB (2005) Plant adaptation regions: ecological and climatic classification of plant materials. Rangeland Ecol Manage 58:315-319

24. Zeiders KE (1984) Helminthosporium spot blotch of switchgrass in Pennsylvania. Plant Dis 68:120-122 